\title{
EXPERIMENTAL STUDY OF STRUCTURAL-MECHANICAL PROPERTIES OF HEAVY OIL
}

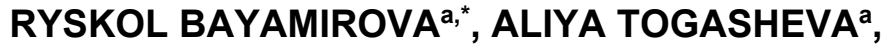 \\ AKSHYRYN ZHOLBASSAROVA ${ }^{a}$, ZHARAS ISLAMBERDIYEV ${ }^{a}$, \\ MAX BISSENGALIEV ${ }^{b}$, DADEN SUIEROV
}

\begin{abstract}
Structural-mechanical properties of heavy oil from Kazakhstan deposits under the heat treatment were studied in this work. The most important and the least studied issues in the technology for the preparation and collection of oil products is the evaluation of the structural and mechanical properties of heavy oils and emulsions and ways to regulate formation them. A feature of the wells operation of fields with high viscosity oils is a sharp increase in water cut at the initial stage of development, which is associated with an excessively large difference in the rheological characteristics of reservoir oil and water. The formation of stable emulsions does not allow for the effective separation of oil from water and leads to a deterioration in product quality. In this regard, in modern conditions of intensification of hydrocarbon production, consideration of the options for the formation and destruction of complex emulsions is a prerequisite for the effective operation of oilfield treatment facilities. Therefore, the research relevance is of reducing the irretrievable losses of hydrocarbons in production systems and study the physical-chemical, structural-mechanical properties of heavy oils emulsions and to develop methods for their regulation, as well as improving oil treatment devices.
\end{abstract}

Keywords: heavy oil, asphaltene, tar, water-oil emulsions, structural-mechanical properties

\section{INTRODUCTION}

Increasing of viscosity and yield strength of heavy crude oil makes the preparation process for transporting much more complicated, starting pressure of pumps gets higher [1-4].

\footnotetext{
a Yessenov University, Faculty of Engineering, 32 microdistrict, 130003, Aktau, Kazakhstan

b Atyrau University of Oil and Gas, Faculty of Oil and Gas, md. Railway station, st. Baimukhanova, 45A, Atyrau, Kazakhstan

*Corresponding author: erzhan-90vko@mail.ru,ryskol.bayamirova@yu.edu.kz
} 
RYSKOL BAYAMIROVA, ALIYA TOGASHEVA, AKSHYRYN ZHOLBASSAROVA, ZHARAS ISLAMBERDIYEV, MAX BISSENGALIEV, DADEN SUIEROV

Thermal treatment is the most commonly used way of preparing highviscous oils for transportation by pipelines [5-8]. Thermal treatment of oils improves rheological properties of oils. Heating the oil to the certain temperature, and then cooling it with constant speed till the temperature of pumping it carried out in static conditions.

Structural-mechanical properties of the paraffin base oil and emulsions thermal treatment study conducted in the laboratory of "Giprovostokneft" [6]. It has been shown that the thermal treatment $\left(50^{\circ} \mathrm{C}\right)$ strongly improves rheological properties of oil in some deposits in Perm Region. For example, Kozubaev's oils viscosity declined from $122.2 \mathrm{cSt}$ to $16.6 \mathrm{cSt}$ before and after thermal treatment.

Authors of work $[8,9]$ shows only the oils with abnormal viscosity and plastic properties can be thermally treated. Thermal treatment of Newton oils doesn't give such an effect. Fast cooling paraffin petroleum oils leads to forming of numerous centers of paraffin crystallization, fine-crystalline system, which increases viscosity and yield point.

Experiments of determining dependence of yield point from thermal treated oil of Mangyshlak deposits with the temperature of $50^{\circ} \mathrm{C}, 70^{\circ} \mathrm{C}$ and $90{ }^{\circ} \mathrm{C}$ have shown that Mangyshlak's oil, treated with $90^{\circ} \mathrm{C}$ has the least yield point than the untreated one. Moreover, the higher the yield point, the higher the effect of thermal treatment on the oil [25]. With the speed of cooling $10^{\circ} \mathrm{C}$ per 1 hour (after thermal treatment $90^{\circ} \mathrm{C}$ ) non-Newton properties of Mangyshlak oil begin to show up while being at lower temperatures (lower than $20-15^{\circ} \mathrm{C}$ ). Changing of viscosity with all temperatures of thermal treatment shows that the oil heated up to 50,80 and $110^{\circ} \mathrm{C}$ cooled down afterwards, has a higher viscosity, than the one that was treated with $90^{\circ} \mathrm{C}$. The lowest viscosity is seen at the cooling speed of $10^{\circ} \mathrm{C}$ per hour [10]. Thermal treatment till $150^{\circ} \mathrm{C}$ leads decreasing of effective viscosity in all the interval of temperatures for almost 3 times, and absence of yield point at a temperature higher than $65^{\circ} \mathrm{C}$.

Thermal treatment of Ozen's oil showed, that thermal treated petroleum, cooled down after thermal treatment till $30^{\circ} \mathrm{C}$ with the speed of cooling $20^{\circ} \mathrm{C}$ per hour, with all temperatures of treatment $\left(50^{\circ} \mathrm{C}, 80^{\circ} \mathrm{C}, 90^{\circ} \mathrm{C}, 100^{\circ} \mathrm{C}\right)$ are Newton liquids. With all other temperatures (lower than $30^{\circ} \mathrm{C}$ ) thermal treated Mangyshlak's oil is viscous-plastic liquid, according to the law of ShvedovBingham.

Mechanism of decreasing of viscosity during the thermal treatment of paraffin base oils is demonstrated in the following ways: During the heating of oil higher than the temperature of melting point of paraffin, oil becomes a homogenous Newton liquid. Cooling process of oil in static condition crystals of paraffin covered with asphaltene-resin substances. The protective layer of asphaltene-tar substances that forms on the crystals during this process, hinder the forming of other layers of paraffin on the surface of crystals. 
It should be mentioned, that current works on thermal treatment of the oil are related to the paraffin based oils. Thermal treatment researches of highly resinous oils are almost absent.

In modern conditions of intensification of the production of hydrocarbon, considering the options for developing the structural-mechanical properties of heavy oils are an essential condition for an effective exploitation of the oil preparing structures. Therefore, the experiments regarding the impact of thermal treatment on the structural-mechanical properties of the highly resinous oils from the West Kazakhstan are interesting not only because of an understanding of their behavior, but also for comparative analysis with the thermal treatment of the paraffin oils.

\section{RESULTS AND DISCUSSION}

It is known that the changing of viscosity of the paraffin based oils after thermal treatment is explained by the ability of paraffin to crystallize in different forms after the heating. During the thermal treatment of highly resinous oils, irreversible processes leading to decreasing of the yield point and partly the structural viscosity take place.

Table 1. Rheological parameters of the oil of the North Buzachi before and after the thermal treatment.

\begin{tabular}{|c|c|c|c|c|c|}
\hline $\begin{array}{c}\text { Without thermal } \\
\text { treatment at } \\
30^{\circ} \mathrm{C}\end{array}$ & $\begin{array}{c}\text { Heating temperature at } 70^{\circ} \mathrm{C}, \\
\text { final cooling temperature is } \\
60^{\circ} \mathrm{C} \text {, cooling speed }- \\
12^{\circ} \mathrm{C} / \text { hour }\end{array}$ & $\begin{array}{c}\text { Heating temperature at } 85^{\circ} \mathrm{C} \text {, } \\
\text { final cooling temperature is } 70^{\circ} \mathrm{C}, \\
\text { cooling temperature until } 60^{\circ} \mathrm{C} \\
\text { is } 50^{\circ} \mathrm{C} / \text { hour, until } 2{ }^{\circ} \mathrm{C} \text { is } \\
10^{\circ} \mathrm{C} / \mathrm{hour}\end{array}$ \\
\hline $\mathrm{P}, \mathrm{Pa}$ & $\mathrm{V}, \mathrm{s}^{-1}$ & $\mathrm{P}, \mathrm{Pa}$ & $\mathrm{V}, \mathrm{s}^{-1}$ & $\mathrm{P}, \mathrm{Pa}$ & $\mathrm{V}, \mathrm{s}^{-1}$ \\
\hline 79.7 & 3.4 & 80.0 & 4.4 & 78.9 & 4.8 \\
\hline 147.9 & 6.9 & 150.3 & 7.6 & 148.8 & 9.2 \\
\hline 219.3 & 11.0 & 233.3 & 13.2 & 218.6 & 13.8 \\
\hline 248.9 & 13.1 & 288.7 & 18.2 & 288.4 & 18.8 \\
\hline 292.2 & 16.3 & 323.6 & 20.6 & 323.3 & 21.3 \\
\hline 355.2 & 21.1 & 358.5 & 23.5 & 358.2 & 24.9 \\
\hline 389.7 & 23.9 & 393.4 & 26.0 & 393.2 & 26.9 \\
\hline 435.4 & 27.4 & 432.8 & 28.7 & 428.1 & 29.4 \\
\hline 463.7 & 30.1 & 468.1 & 31.5 & 463.0 & 32.2 \\
\hline 502.1 & 32.2 & 504.8 & 34.7 & 500.4 & 35.2 \\
\hline 532.8 & 35.7 & 527.4 & 37.7 & 532.8 & 38.2 \\
\hline
\end{tabular}


RYSKOL BAYAMIROVA, ALIYA TOGASHEVA, AKSHYRYN ZHOLBASSAROVA, ZHARAS ISLAMBERDIYEV, MAX BISSENGALIEV, DADEN SUIEROV

In table 2 the results of the experiments on the thermal treatment of some heavy oils from the West Kazakhstan are demonstrated. The thermal treatment of the highly resinous oils does not effect on viscosity so much, but it does strongly effect on the yield point.

Table 2. Results of the experimental data of the thermal treatment of the heavy oils of some deposits of the West Kazakhstan.

\begin{tabular}{|c|c|c|c|c|}
\hline Deposit & Condition & $\begin{array}{l}\text { Thermal treatment } \\
\text { temperature, }\left[{ }^{\circ} \mathrm{C}\right]\end{array}$ & $\begin{array}{c}\text { Cooling speed, } \\
{\left[{ }^{\circ} \mathrm{C} / \mathrm{h}\right]}\end{array}$ & $\begin{array}{c}\text { Yield point at } \\
30^{\circ} \mathrm{C},[\mathrm{Pa}]\end{array}$ \\
\hline \multirow{3}{*}{$\begin{array}{c}\text { North } \\
\text { Buzachi }\end{array}$} & \begin{tabular}{|c|}
$\begin{array}{c}\text { Before thermal } \\
\text { treatment }\end{array}$ \\
\end{tabular} & - & - & 72.5 \\
\hline & \multirow{2}{*}{$\begin{array}{c}\text { After thermal } \\
\text { treatment }\end{array}$} & 70 & 12 & 6.3 \\
\hline & & 85 & 12 & 3.9 \\
\hline \multirow{3}{*}{ Karazhanbas } & $\begin{array}{c}\text { Before thermal } \\
\text { treatment }\end{array}$ & - & - & 66.8 \\
\hline & \multirow{2}{*}{$\begin{array}{c}\text { After thermal } \\
\text { treatment }\end{array}$} & 70 & 12 & 4.9 \\
\hline & & 85 & 12 & 2.8 \\
\hline \multirow{3}{*}{ Karaturisk } & $\begin{array}{c}\text { Before thermal } \\
\text { treatment }\end{array}$ & - & - & 69.8 \\
\hline & \multirow{2}{*}{$\begin{array}{c}\text { After thermal } \\
\text { treatment }\end{array}$} & 70 & 12 & 4.9 \\
\hline & & 85 & 12 & 2.8 \\
\hline \multirow{3}{*}{ Kalamkas } & $\begin{array}{c}\text { Before thermal } \\
\text { treatment }\end{array}$ & - & - & 69.7 \\
\hline & \multirow{2}{*}{\begin{tabular}{c|} 
After thermal \\
treatment
\end{tabular}} & 70 & 12 & 6.9 \\
\hline & & 85 & 12 & 5.5 \\
\hline
\end{tabular}

In the oil industry the traditional method is deconstruction of emulsions by thermochemical way, which is continuously developing and is used together electrical fields and hydrodynamic characteristics of the flow [11-23, 33]. Heavy hydro-petroleum emulsions water drops of which are surrounded by strong protective shells, consisting of asphaltene-resin substances and mechanical admixtures are stable emulsions. Destruction of these emulsions by simple ways is way more complicated.

An important factor in the process of destruction of the emulsion is a hydrodynamic impact. Intensity of the destruction of emulsions is not affected much by the settling time as a factor of unmixable substances always taken into consideration during an elaboration of the projects of oil treatment plants, but manifesting hydrodynamic demolishing of the water globules at an intensive flow turbulence. Some experimental results showed hydrodynamic demolishing is a more effective way of destruction of the emulsions. Thus hydrodynamic method of destruction of the emulsion can be used as the most effective in the technology of oil treatment and in construction of a heavy-duty continuous emulsion breakers. 
The movement of the gases, going into the receptacle with the oil product is usually followed by a formation of bubbles and it pushes the liquid. The layers of the liquid surrounding the stream are moved according to the movement of the stream. Therefore, part of the movement of the liquid is transferred to the surrounding liquid. At the same moment the speed of the liquid captured by the moving stream is less than the speed of the stream which was captured by the liquid.

Each of the layers of the liquid come into motion makes other calm layers in its vicinity which did not before to the movement. The stream has a bigger cut the further it is from the beginning and the less its speed is. When the surrounding liquid is captured by the stream and come to the motion, it creates a rarefaction for some time in the space it covered before. Lowering of the pressure makes surrounding and calm liquids get sucked into that part of the space. Kinetic energy of the stream, which appears in the process of liquid suction from the external environment is dependent to the starting speed of the leaking from nozzle.

The liquids located very close to the surface comes to motion and proceeds towards the surface by the impact of a tangential stress during the rising of bubbles. The rarefaction appears after the rising bubbles which can explain the suction of the liquid from the surrounding volume. The size of the bubbles is defined by the pressure of the gas inside of the bubble and by the outer hydrostatic pressure, which responds to the height of the pillar of the liquid above the bubble. Hydrostatic pressure inside of the liquid is continuously changing towards the surface, so, the size of the bubbles increases. The shape of bubbles is deviated from being a ball, and the way of movement by vertical line, collisions between the bubbles will take place, simultaneously with the bubbles growing of the volume of the them. An increasing of size of the bubble creates an enormous interfacial area between the bubble and the surface, in other words, a free bubbling takes place. The liquid pushed out by the gas leaks towards the periphery of reservoir and goes down to the trough after the gas went to the surface.

If we consider a condition in which the bubble appears inside of the liquid. The pressure of the liquid hampers the creation of the bubble when the gas under pressure goes to the liquid. The pressure of the liquid can be overcome by the pressure of the gas, and also by the surface stress. As soon as the bubble appears. It gets affected by the buoyancy power. The bubble gets of the estuary and rises up at the moment when the buoyancy power overcomes the surface tension.

For the ball shaped bubble with the diameter of $d$ the buoyancy power can be defined by the following formula: 


$$
\mathrm{G}_{1}=\frac{1}{6} \pi \mathrm{d}^{3}\left(\gamma_{1}-\gamma_{\mathrm{g}}\right)
$$

In which $\gamma_{1}-$ specific weight of the liquid; $\gamma_{g}-$ specific weight of the gas.

If the specific weight of the liquid is noticeably more than specific weight of the gas, we can neglect the $\gamma_{g}=0$.

The speed of the rising of bubbles during its way through the layer of the liquid mainly depends on its viscosity, specific weights of gas and liquid, yield point and the size of the bubble. Temperature effects on viscosity, yield point and specific weigh, and therefore on the speed of rising of bubbles. That is why different formulas related to different hydrodynamic conditions are used for defining the speed of the rising bubble.

The speed of the rising bubble can be approximately found according to the balance with the resistance against the motion of the bubble:

$$
v=2 \sqrt{\frac{\mathrm{dg}}{3 \psi}}
$$

Where $\psi$ is a coefficient of resistance, which depends on the motion regime and the Reynold's number:

$$
\operatorname{Re}=\frac{v d \rho}{\mu}
$$

At $\operatorname{Re} \leq 2$ laminar-flow conditions take place, and the coefficient of resistance has a value of:

$$
\psi=\frac{24}{\operatorname{Re}}
$$

If we put this value in the equation (2) we get the Stokes formula:

$$
v=\frac{\mathrm{d}^{2}\left(\gamma_{1}-\gamma_{\mathrm{g}}\right)}{18 \mu}
$$

Furthermore, for the speed of rising the coefficient of resistance at the $\operatorname{Re} \leq 2$ (laminar flow), and also for the bubble flow will be equal to $\psi=24 / \operatorname{Re}$, so, the Stokes formula can be used for defining the speed of the motion.

The coefficient of resistance for the turbulent region can be written as $\psi=8 / 3$ [24]. If it is put in the formula (2), we can get the speed of the rising of the bubble, in cases when we can neglect the specific weight of the gas compared to the specific weight of the liquid. 
Imagine that during the motion of the bubble inside resistant powers which are conditioned by the viscous and plastic properties are added to each other. Then the formula for the power of resistance can be demonstrated as [26]:

$$
\omega_{\mathrm{n}}=\pi \mathrm{d}^{2} \tau_{0}+3 \pi \eta \mathrm{d} v
$$

Equalizing (10) to the resultant power:

$$
v=\frac{d}{3 \eta}\left[\frac{\left(\rho_{1}-\rho_{\mathrm{g}}\right) \mathrm{gd}_{\mathrm{g}}}{6}-\tau_{0}\right]
$$

For the power law fluid in work, we can use the following formula:

$$
v=\frac{1}{3}\left[\frac{\mathrm{d}_{\mathrm{g}}\left(\rho_{\mathrm{l}}-\rho_{\mathrm{g}}\right) \mathrm{g}}{6 \kappa}-\tau_{0}\right]^{\frac{1}{\mathrm{n}}} \mathrm{d}_{\mathrm{g}}
$$

Where $\mathrm{n}$ and $\mathrm{k}$ - indicators of non-newton behavior (consistency);

$$
\mathrm{c}_{\omega}=\frac{8 \cdot 3^{\mathrm{n}}}{\operatorname{Re}}, \operatorname{Re}=\frac{\rho_{\mathrm{l}} v_{\mathrm{g}}^{2-\mathrm{n}} \mathrm{d}_{\mathrm{g}}^{2}}{\kappa}
$$

At $n=1$ formulas (8) and (9) transit to the formula for the viscous liquid. It should be mentioned that if the system of nozzles is used for the gas supply the ratio below is not lost in case, that the distance between two centers of the neighbor estuaries is equal to the diameter of bubbles.

The difference between velocities of the gas flow and petroleum product provides the creation of tangential strains lead to deformation of drops, because of the tangential strain, interfacial tension, which makes droplets decrease their surface. Even though the existence of emulsion breakers makes the process of decreasing the toughness of heavy emulsion and destruction of the background shell of the water-oil emulsion much easier.

Singled bubbles do not appear at the high enough speed of the gas in the estuary of the opening, but a gas flow which divides in bubbles leaks.

Liquid droplets deform after getting into the warm air flow and the internal motion appears inside of them. Development of this processes leads to deformation and deconstruction of an armor-plate shell of the emulsion droplets. A type of process of their splitting process according to the speed of the flow and physical parameters of gas and droplets of emulsions can be different. In the work [28] deformations of bubbles and splitting of droplets in gas flows 
were discussed. It is shown that the process of deconstruction depends on the speed of the gas flow, density and viscosity of liquid and gas environment, surface stress, time of the impact, diameter of globules and acceleration. Splitting of droplets is mainly represented by the Webber number We and Laplace Lp:

$$
W e=\frac{2 a \rho_{g} g v^{2}}{\sigma}, \operatorname{Lp}=\frac{2 a \rho_{21} \sigma}{\mu_{1}^{2}}
$$

where a - radius of the droplet; $v$ - speed of the gas flow; $\mu$-dynamic viscosity of the liquid.

The maximal splitting of the droplet comes to reality in some diapason of Weber numbers, limited by some critical numbers, depending on the Laplace liquid.

As it is known in oil industry, the traditional way of destruction of emulsions is by thermochemical way, which is continuously developing and is used with electrochemical fields and hydrodynamic properties of the flow [29-32].

Conditions of the oil preparation process strongly depend on the condensation of natural emulsifiers (asphaltene, paraffin, resin and etc.) which create entrained highly viscous emulsion. Destruction of this emulsion in traditional preparing apparatuses is followed by an enormous wasting of emulsion breakers, heat, electric energy and long settling period. That is why right complex impact on emulsions makes emulsion breaks easier.

A hydro mixing receptacle with the pipes with openings was constructed in the laboratory for researches of the impact of hydrodynamic effect on emulsion breaks. The amount and the diameter of the openings provides the speed of the flow of 1-3.5 m/s, experiments were done on the emulsions of the oil from the deposit of Karazhanbas. Researches were made with $20 \%$ emulsion at the temperature of $20^{\circ} \mathrm{C}$ and $40^{\circ} \mathrm{C}$. The preparation of the emulsion carried out on the emulsifier.

Results of the laboratory works have shown that hydrodynamic demulsification is more effective than simple thermochemical settling and emulsion breaking. For example, at the thermochemical method during the usage of dissolvan $4411-100 \mathrm{~g} / \mathrm{t}$, the amount of emitted water at the temperature $40{ }^{\circ} \mathrm{C}$ is $40 \%$, and the usage of the energy of the flow is $90 \%$.

\section{CONCLUSION}

The way of heating by using the energy of the flow is one of the effective ways of intensification of destruction of stable oil-water emulsions. To conclude everything that was written in this work, it can be said, that the research of the 
thermal method of developing of structural-mechanical properties of heavy oils shows that the thermal treatment of oils from the deposits of North Buzachi negligibly effects on their viscosity, but hugely on lowering the yield point. By experimental results can be shown the rheological parameters of the North Buzachi oil before and after the thermal treatment at temperature $70^{\circ} \mathrm{C}$ with final cooling temperature $60^{\circ} \mathrm{C}$ viscosity of oils from 4.4 to $37.7 \mathrm{~s}^{-1}$. In other case, at temperature $85^{\circ} \mathrm{C}$ with final cooling temperature $70{ }^{\circ} \mathrm{C}$ viscosity of oils increased from 4.8 to $38.2 \mathrm{~s}^{-1}$.

According to results of experimental study can be offered an improved oil preparation set for heating heavy oils and oil-water emulsions. This oil preparation set provides a high level of heating and dehydration of heavy oils and emulsions with integrated effect on the process of temperature and hydrodynamic factors.

\section{EXPERIMENTAL SECTION}

Experiments considering the research of the impact of the thermal treatment on the structural-mechanical properties of the oils from North Buzachi, Karazhanbas and Kalamkas were conducted in the laboratory. The structuralmechanical properties of thermal treated oil were scrutinized with using capillary viscometer. The starting temperature of heating and the speed of cooling affect the effectiveness of thermal treatment, that is experiment oil was heated up to $70{ }^{\circ} \mathrm{C}$ and cooled down to $30^{\circ} \mathrm{C}$ with the speed of $12^{\circ} \mathrm{C}$ per hour (Table 1). The effectiveness of the thermal treatment was defined by comparing of the rheological parameters of the oil before and after heat treatment.

Proposed installation is shown in the Figure 1 [24]. The installation consists of reservoir 1 , filled with viscous petroleum product 2 , also the air duct 3 with hoses 4 , connected to a pipe 5 for a high-pressure heated air on the heating unit by a concentrator or an electric heater. Air extracting from the reservoir 1 is done by the pressure reducing valve 7 adjusted to $1.5-2 \mathrm{~atm}$., through which the exhausted air goes to the heating. There is a pipe 9 in the lowest part of the conical shaped cap of the reservoir for collecting and pulling out condensed water.

Compressed air goes from the compressor to the heating unit 6 , heated by the sun concentrator or by the electric heater till $90-100^{\circ} \mathrm{C}$. The electrical heater is used at the low intensity of the sun flow and an insufficient air heating. Then, the hot pressed air goes through the pipe 5 goes to the air duct 3 of the reservoir 1 to the hoses 4 , where the stream of the hot air flows to the petroleum product 2 through the openings in the hoses, and then goes up as a vapor-air foam. 
The high intensity is existing due to the transitional behavior of the gas-dynamic impact of the hot compressed air to the changing viscosity of oil products, resisting by the vapor-air foams followed by a breakup. As a result, it condenses on the conical shaped cap of the reservoir 1 from the vapor-air foams, and leaks by an oblique surface to the pipe 9 by the bottom of the cap and disappears. An air withdrawal goes by the reduction valve 7 , adjusted to the pressure of 1.5-2 atm. and supplied through the channel 8 , to the heating unit 6.

The given construction allows heat the oil product in the reservoir more intensively, dehydrate and save the energy resources during the preparation and transporting.

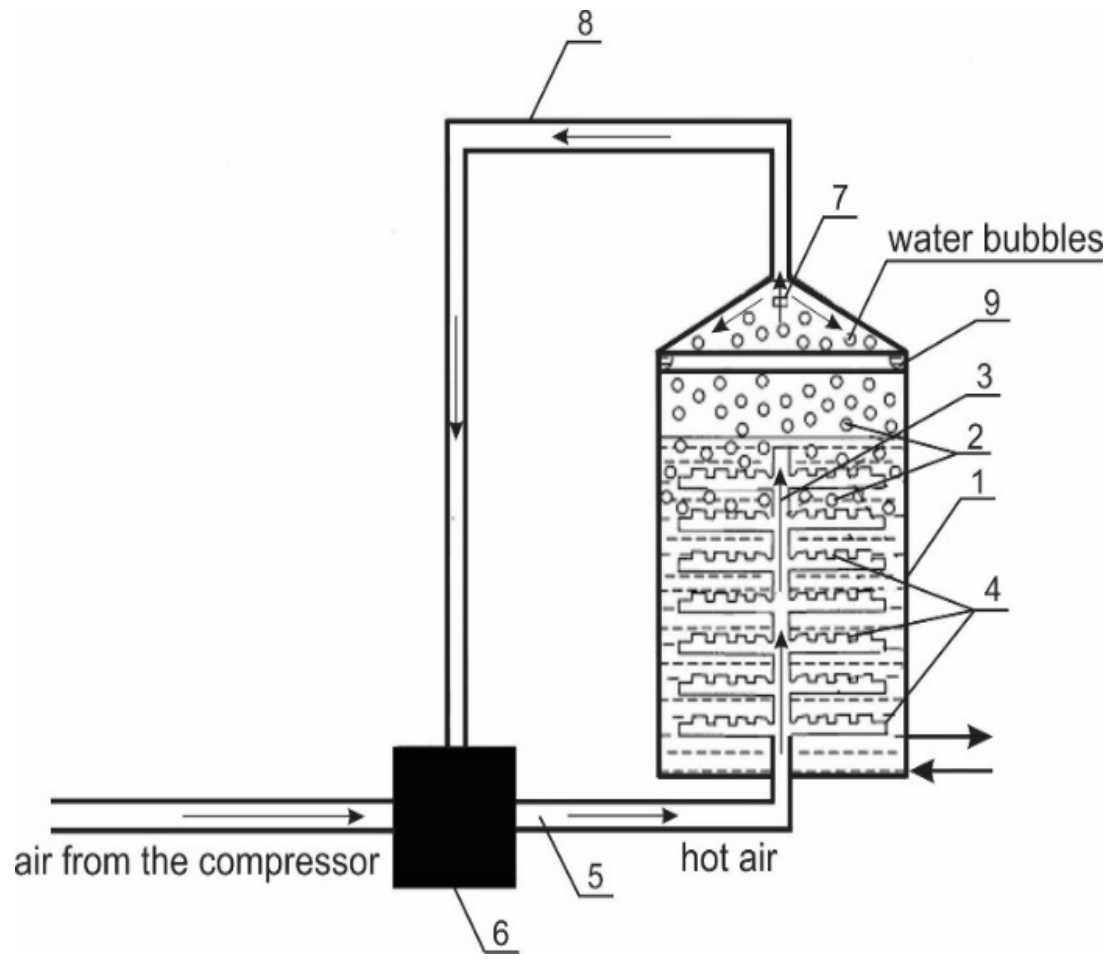

1 - reservoir; 2 - oil product; 3 - air duct; 4 - hoses; 5 - pipeline; 6 - heating unit; 7 - valve; 8 - withdrawing; 9 - channel

Figure 1. Scheme of the installation for the heating of the water-oil emulsions 


\section{REFERENCES}

1. A. Kh. Mirzadzhanzade; A. K. Gallyamov; B. I. Maron; V. A. Yufin; Hydrodynamics of pipeline transportation of oil and oil products, Nedra, Moscow, 1984, p. 286. (In Russian)

2. I. N. Evdokimov; N. Yu. Eliseev; D. Yu. Eliseev; J. Petrol. Sci. Eng., 2001, 30, 199-211

3. S. O. Ilyin; M. P. Arinina; M. Yu. Polyakova; V. G. Kulichikhin; A. Ya. Malkin; Fuel, 2016, 186, 157-167

4. K. Moussa; M. Djabourov; J. L. Volle; Fuel, 2004, 83, 1591-1605

5. R. M. Webber; J. Rheol., 1999, 43, 911-931

6. S. W. Hasan; M. T. Ghannam; N. Esmail; Fuel, 2010, 89, 1095-1100

7. S. Ilyin; M. Arinina; M. Polyakova; G. Bondarenko; I. Konstantinov; V. Kulichikhin; A. Malkin; J. Petrol. Sci. Eng. 2016, 147, 211-217

8. S. O. Ilyin; M. P. Arinina; Y. S. Mamulat; A. Y. Malkin; V. G. Kulichikhin; Colloid J., 2014, 76, 425-435

9. A. M. McKenna; L. J. Donald; J. E. Fitzsimmons; P. Juyal; V. Spicer; K. G. Standing; A. G. Marshall; R. P. Rodgers; Energ. Fuel., 2013, 27, 1246-1256

10.B. Sorina; A. Tamas; Studia UBB Chemia, 2013, 58, 21-30

11.A. Gaspar; E. Zellermann; S. Lababidi; J. Reece; W. Schrader; Energ. Fuel., 2012, 26, 3481-3487

12.A. Y. Malkin; S. N. Khadzhiev; Pet. Chem., 2016, 56, 541-551

13.A. Tamasa; M. Vincze; Studia UBB Chemia, 2011, 56, 247-255

14.I. A. Wiehe; Energ. Fuel., 2012, 26, 4004-4016

15.E. Rogel; C. Ovalles; J. Vien; M. Moir; Fuel, 2016, 178, 71-76

16.C. Tudose; L. Patrascu; P. Alexe; Studia UBB Chemia, 2014, 59, 87-102

17.R. Z. Syunyaev; R. Z. Safieva; R. R. Safin; J. Petrol. Sci. Eng., 2000, 26, 31-39

18.F. Yziquel; P. J. Carreau; M. Moan; P. A. Tanguy; J Non-Newton. Fluid, 1999, 86, 133-155

19.J. Zhang; X. Chen; D. Zhang; J. Xu; J. Petrol. Sci. Eng., 2017, 156, 563-574

20.W. S. Hasan; M. T. Ghannam; N. Esmail; Fuel, 2010, 89, 1095-1100

21.C. Chang; Q. D. Nguyen; H. P. Ronningsen; J. Non-Newton Fluid, 1999, 87, 127154

22.M. Fingas; B. Fieldhouse; Mar. Pollut. Bull., 2003, 47, 369-396

23.Y. Imanbayev; Y. Tileuberdi; Y. Ongarbayev; Z. Mansurov; A. Batyrbayev; Y. Akkazin; E. Krivtsov; A. Golovko; S. Rudyk; Eurasian Chem. Technol. J., 2017, $19,147-154$

24. M. D. Bissengaliyev; M. E. Baymirov; Kazakhstan patent 20504, 2008. (In Russian)

25.J. A. Boxall; C. A. Koh; E. D. Sloan; A. K. Sum; D. T. Wu; Ind. Eng. Chem. Res., 2010, 49, 1412-1418

26.P. Sherman; Encyclopedia of emulsion technology, Marcel Dekker, New York, 1983, p. 725

27.M. R. Khan; Energ. Source., 1995, 18, 385-391 
RYSKOL BAYAMIROVA, ALIYA TOGASHEVA, AKSHYRYN ZHOLBASSAROVA, ZHARAS ISLAMBERDIYEV, MAX BISSENGALIEV, DADEN SUIEROV

28.A. Siavash; S. Mehdi; M. Mohammad; M. S. Mehdi; Egypt. J. Pet., 2017, 26, 209213

29.S. N. Ashrafizadeh; E. Motaee; V. Hoshyargar; J Pet. Sci. Eng., 2012, 86-87, 137143

30.R. Martínez-Palou; M. L. Mosqueira; B. Zapata-Rendón; E. Mar-Juárez; C. BernalHuicochea; J. C. Clavel-López; J. Aburto; J. Pet. Sci. Eng., 2011, 75, 274-282

31.S. Ashrafizadeh; M. Kamran; J. Pet. Sci. Eng., 2010, 71, 205-211

32.Y. Ongarbayev; A. Golovko; E. Krivtsov; E. Tileuberdi; Y. Imanbayev; B. Tuleutayev; Z. Mansurov; Studia UBB Chemia, 2014, 59, 57-64 